Supporting Online Material for:

\title{
Enhanced climate variability in the tropics: A 200,000 yr annual record of monsoon variability from Pangea's equator
}

\author{
Roger Y. Anderson
}

Department of Earth and Planetary Sciences, University of New Mexico, Albuquerque NM, 87131, USA

\section{S 1. Data, Compilation, and Analysis}

Castile couplet thickness data are from University of NM No. 1 Core, presently archived at USGS core storage facility, Denver, CO. The single core collected the entire Castile Formation and recovery was virtually $100 \%$. For reasons of economy, the core was collected from a region in the basin where halite layers were dissolved from the formation, resulting in fractures and minor interruptions in continuity. The thickness of annual sulfate layers from cores where halite was present were substituted for halite interruptions before $T_{0}+100 \mathrm{kyr}$, with varve number and thickness interpolated thereafter. Discontinuities had little effect on variance in spectra, as observed by comparing segments of differing length and positions in the core.

Each pair (couplet) of carbonate and sulfate laminae was interpreted by R. Y. Anderson, individually measured, and compiled into a continuous annual series. A second, decadal series was assembled from the sum of 10 consecutive annual values. Methods of series reconstruction are published (Anderson, 1982, text reference). Estimates of period and spectral power were obtained by applying standard methods of series processing and spectral analysis to segments of the series between $T_{0}+11 \mathrm{kyr}$ to $T_{0}+173\left(T_{0}\right.$ is the oldest varve in the series, near the base of the core).

Data in Table 1 are for decadal values in Castile series cropped at 2 std. dev. above a 1-kyr running mean and re-sampled at $1 \mathrm{kyr}$ by linear interpolation.

Table 1. Castile series. Mean couplet thickness.

$\begin{array}{llllllll}\text { Year } & \mathrm{mm} & \text { Year } & \mathrm{mm} & \text { Year } & \mathrm{mm} & \text { Year } & \mathrm{mm} \\ 11000 & 0.91 & 51000 & 1.86 & 91000 & 1.73 & 131000 & 1.81 \\ 12000 & 1.00 & 52000 & 1.97 & 92000 & 1.97 & 132000 & 1.68 \\ 13000 & 0.95 & 53000 & 1.87 & 93000 & 1.78 & 133000 & 1.14 \\ 14000 & 1.23 & 54000 & 3.44 & 94000 & 1.85 & 134000 & 0.70 \\ 15000 & 1.41 & 55000 & 2.91 & 95000 & 1.53 & 135000 & 1.10 \\ 16000 & 1.02 & 56000 & 2.56 & 96000 & 1.58 & 136000 & 1.71 \\ 17000 & 1.26 & 57000 & 2.27 & 97000 & 1.33 & 137000 & 1.66 \\ 18000 & 1.14 & 58000 & 2.37 & 98000 & 1.53 & 138000 & 2.23 \\ 19000 & 1.45 & 59000 & 1.60 & 99000 & 1.71 & 139000 & 1.51 \\ 20000 & 1.31 & 60000 & 1.86 & 100000 & 2.14 & 140000 & 1.89 \\ 21000 & 1.28 & 61000 & 1.50 & 101000 & 1.76 & 141000 & 1.65 \\ 22000 & 1.41 & 62000 & 1.64 & 102000 & 2.20 & 142000 & 2.17\end{array}$




\begin{tabular}{|c|c|c|c|c|c|c|c|}
\hline 23000 & 1.47 & 63000 & 1.62 & 103000 & 2.42 & 143000 & 2.14 \\
\hline 24000 & 1.35 & 64000 & 1.92 & 104000 & 2.19 & 144000 & 1.43 \\
\hline 25000 & 1.57 & 65000 & 1.91 & 105000 & 2.04 & 145000 & 2.30 \\
\hline 26000 & 0.73 & 66000 & 2.08 & 106000 & 1.55 & 146000 & 2.10 \\
\hline 27000 & 1.93 & 67000 & 3.15 & 107000 & 0.21 & 147000 & 2.22 \\
\hline 28000 & 2.05 & 68000 & 2.04 & 108000 & 0.25 & 148000 & 1.64 \\
\hline 29000 & 2.02 & 69000 & 2.86 & 109000 & 1.12 & 149000 & 2.23 \\
\hline 30000 & 1.87 & 70000 & 2.12 & 110000 & 1.52 & 150000 & 2.03 \\
\hline 31000 & 1.90 & 71000 & 2.23 & 111000 & 1.56 & 151000 & 1.84 \\
\hline 32000 & 2.07 & 72000 & 2.03 & 112000 & 1.98 & 152000 & 1.74 \\
\hline 33000 & 1.67 & 73000 & 2.10 & 113000 & 1.60 & 153000 & 1.57 \\
\hline 34000 & 1.56 & 74000 & 2.19 & 114000 & 1.34 & 154000 & 1.81 \\
\hline 35000 & 1.69 & 75000 & 2.26 & 115000 & 1.36 & 155000 & 1.25 \\
\hline 36000 & 1.48 & 76000 & 2.17 & 116000 & 1.56 & 156000 & 1.69 \\
\hline 37000 & 0.93 & 77000 & 2.33 & 117000 & 2.10 & 157000 & 1.61 \\
\hline 38000 & 1.21 & 78000 & 2.17 & 118000 & 1.46 & 158000 & 2.02 \\
\hline 39000 & 1.75 & 79000 & 1.84 & 119000 & 1.51 & 159000 & 1.65 \\
\hline 40000 & 1.29 & 80000 & 2.02 & 120000 & 1.34 & 160000 & 2.58 \\
\hline 41000 & 1.50 & 81000 & 2.09 & 121000 & 1.40 & 161000 & 1.85 \\
\hline 42000 & 0.97 & 82000 & 1.87 & 122000 & 2.57 & 162000 & 1.44 \\
\hline 43000 & 1.00 & 83000 & 2.94 & 123000 & 1.77 & 163000 & 2.09 \\
\hline 44000 & 1.83 & 84000 & 2.01 & 124000 & 2.15 & 164000 & 1.53 \\
\hline 45000 & 2.09 & 85000 & 2.09 & 125000 & 2.13 & 165000 & 2.25 \\
\hline 46000 & 2.28 & 86000 & 1.97 & 126000 & 1.89 & 166000 & 1.71 \\
\hline 47000 & 2.20 & 87000 & 2.21 & 127000 & 1.44 & 167000 & 2.19 \\
\hline 48000 & 2.21 & 88000 & 2.01 & 128000 & 2.10 & 168000 & 1.87 \\
\hline 49000 & 1.91 & 89000 & 1.95 & 129000 & 1.63 & 169000 & 2.49 \\
\hline \multirow[t]{4}{*}{50000} & 2.20 & 90000 & 2.35 & 130000 & 1.40 & 170000 & 1.65 \\
\hline & & & & & & 171000 & 1.21 \\
\hline & & & & & & 172000 & 2.10 \\
\hline & & & & & & 173000 & 1.06 \\
\hline
\end{tabular}

\section{S2. Supplementary Text Figures and Explanation}

\section{S2.1 Basin Hydrology}

The deep basin in which Castile evaporite varves precipitated was encircled by a tall reef that today is host of Carlsbad Caverns, NM (Fig. S1). Once partly isolated from the ocean, evaporating chloride brine in the basin was recharged by seepage of marine water through the reef and by groundwater. The water table (lake level) was maintained by a balance between recharge plus minor atmospheric precipitation on the lake's surface and evaporation plus reflux of dense brine through the reef. The lake received negligible runoff (see Kirkland, 2003, text reference). Under ordinary climatic conditions, when 
calcite laminated anhydrite precipitated from the brine's surface, a pycnocline separated an upper circulating lake from a thick layer of dense, non-circulating brine at depth (Fig. S1a). Under exceptionally hot-dry conditions, evaporative drawdown and increased brine concentration (density) removed the pycnocline and resulted in overturn, deep mixing of brine, and precipitation of anomalously thick seasonal layers of calcium sulfate (Fig. $\mathrm{S} 1 \mathrm{~b})$. Prolonged episodes of drawdown concentrated brine until layers of halite were seasonally precipitated from the brine's surface. The length of episodes of halite precipitation ranged from a less than 100 years to about 1000 years, in response to a strong quasi-bi-millennial oscillation (QBMO) in surface temperature. (see text Fig. 1d for typical stratigraphic units, and Kirkland, 2003, and Anderson, 1982, text references).

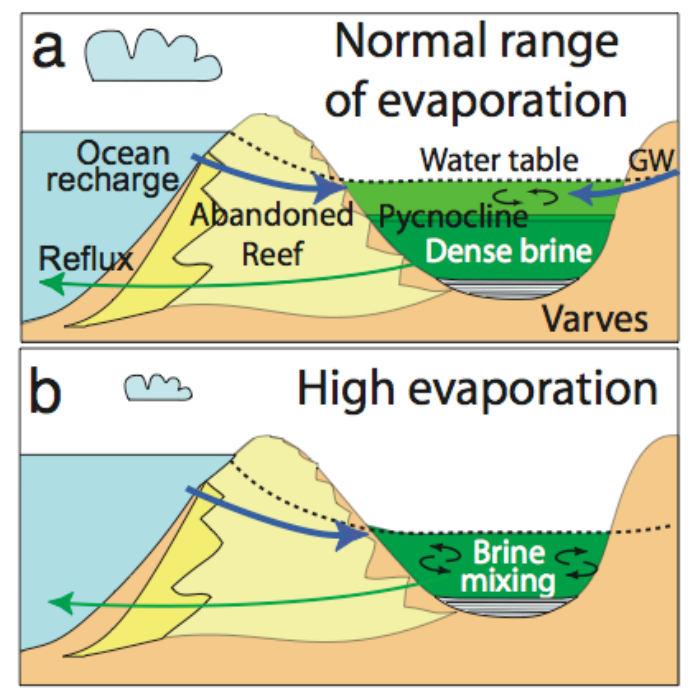

Fig. S1. Diagrammatic cross-section of Castile evaporite basin, with hydrology. a. Basin with usual climate and hydrology. Recharge of ocean water through abandoned reef and by groundwater seepage (GW, blue arrow) and reflux of dense brine through reef (green arrow. Non-circulating, dense brine (dark green) is overlain and separated by a pycnocline from circulating and evaporating brine (lighter green). b. Basin under conditions of high evaporation, drawdown of water level, overturn, and mixing of dense brine.

\section{S2.2 Removal of Overturn Contributions to Variance}

The effect of nonlinear contributions to varve thickness from loss of the pycnocline and brine mixing (anomalously thick sulfate layers), and freshening events on spectral power and frequency was examined by calculating B-T spectra for a series of uncropped decadal thickness values, and values cropped at $5 \mathrm{~mm}$ and $3 \mathrm{~mm}$ (Fig. S2a) (mean value is $1.8 \mathrm{~mm}$ ). Cropping resulted in little to no shift in frequency of any maxima in power. The least loss in power is at frequencies of climatic precession $(23.4$ kyr) and its $4^{\text {th }}$ harmonic (5.4 kyr). Substantial loss in power is seen in the dominant mode of the $2^{\text {nd }}$ harmonic of climatic precession $(11.7 \mathrm{kyr})$, and there is a reversal in power with cropping in the $9.4 \mathrm{kyr}$ mode. The $3^{\text {rd }}$ harmonic of climatic precession $(\sim 7$ kyr) also has substantially reduced power. 
The association between harmonic oscillations in varve thickness and the fundamental precession cycle were further examined by applying a $2 \mathrm{kyr}$ moving variance to the same series of decadal thickness values, which accentuated the abrupt character of changes in thickness at harmonic frequencies (Fig. S2c). An MTM spectrum for variance series resolves both modes of climatic precession whereas power in $2^{\text {nd }}$ and $3^{\text {rd }}$ harmonics is greatly exaggerated relative to that of precession. Exaggeration of power in $2^{\text {nd }}$ and $3^{\text {rd }}$ harmonics appears to be related to both the amplitude and square-wave (abrupt) character of harmonic oscillations and the Fourier method. Harmonic oscillations in the Castile series, although exaggerated in the spectrum, are, nevertheless, real physical cycles.

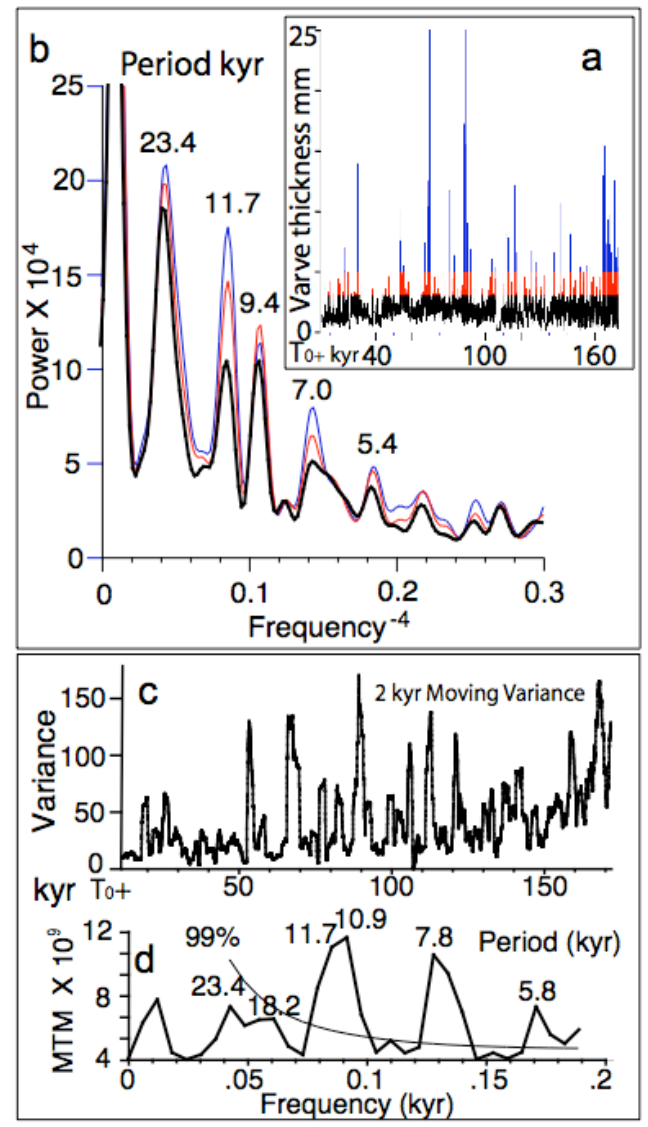

Fig. S2. Effects of brine overturn, freshening, and harmonics on varve thickness and spectra. a. Decadal (raw) series with no cropping of thick values (blue), cropped at $5 \mathrm{~mm}$ (red), and cropped at $3 \mathrm{~mm}$ (black). b. Spectrum of A showing no change in frequency of power from successive cropping (blue, red, black). Minimum loss in power after noise removal is at periods of $23.4 \mathrm{kyr}$ and $5.4 \mathrm{kyr}$. Most loss (noise) is at $11.7 \mathrm{kyr}$ and $7 \mathrm{kyr}$. $\mathrm{B}-\mathrm{T}$ spectrum, resolution $50 \% . \mathrm{N}=16,200$. c. $2 \mathrm{kyr}$ moving variance of series in a cropped at 2 std. dev. above mean. d. Spectrum for series in c showing exaggerated power in harmonics relative to $23.4 \mathrm{kyr}$ and $18.2 \mathrm{kyr}$ modes of CP. MTM resolution 2, tapers $3, \mathrm{~N}=16,200$. 


\section{S2.3 Regional Monsoonal Winds in Western Equatorial Pangea}

Wind vectors obtained by a GCM for the asymmetrical Pangea-Gondwana continent (Pangea A), as calculated by Kutzbach and Ziegler (1988, text reference) depict a reversal in continental (offshore) and maritime (onshore) airstreams over the continent in western equatorial Pangea (Fig. S3). Seasonal wind reversal is prominent and onshore vectors are especially large near and south of the equator during summer solstice in the Southern Hemisphere (SH-SS, red arrows) owing to the much larger landmass in the $\mathrm{SH}$ and its greater effect on outgoing long-wave radiation (OLR). Wind vectors for the winter solstice in the $\mathrm{NH}$ (red arrows north of equator) correspond with wind directions in coeval Pangean dune fields (orange arrowheads, from Parish and Peterson, 1988; Loope et al., 2004; text references), and the season without strong westerly monsoonal flow had generally hot and dry conditions near the equator for $\sim 8$ months of the year.

The hiatus in sulfate that resulted in Castile varves (text Fig. 5c) is thought to represent strong westerly (cool, dry monsoonal) flow over the coastal basin during SS in the $\mathrm{SH}$. Location of the Castile evaporite relative to the equator is imprecisely known and approximated by the black rectangle. GCM indications of strong westerly flow south of the equator during the monsoon season favor a location for the evaporite closer to the equator, but uncertaintly in the reconstruction of Pangea near the equator does not allow further interpretation.

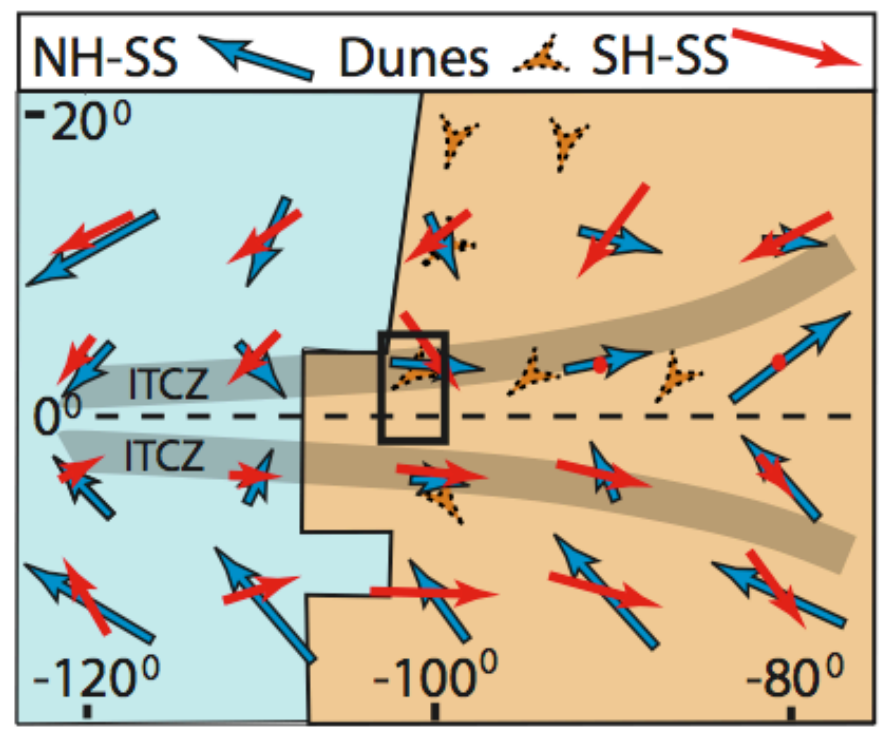

Fig. S3. Wind vectors at summer solstice in SH and NH (from Kutzbach and Ziegler, 1994) and wind directions in Pangean dune fields (from Parish and Peterson, 1988; Loope et al., 2004). Black rectangle is approximate location of Castile varve site. Dunes represent long, dry season (continental monsoon) in $\mathrm{NH}$ centered near winter solstice. 